\title{
Spectrophotometric Evaluation of Crown Fragment a Year After Reattachment Using Fiber-Reinforced Post: A Case Report
}

\author{
KÜÇÜKEKENCİ FUNDAOĞLU Funda ${ }^{1 *}$, KÜÇÜKEKENCİ Ahmet Serkan ${ }^{2}$
}

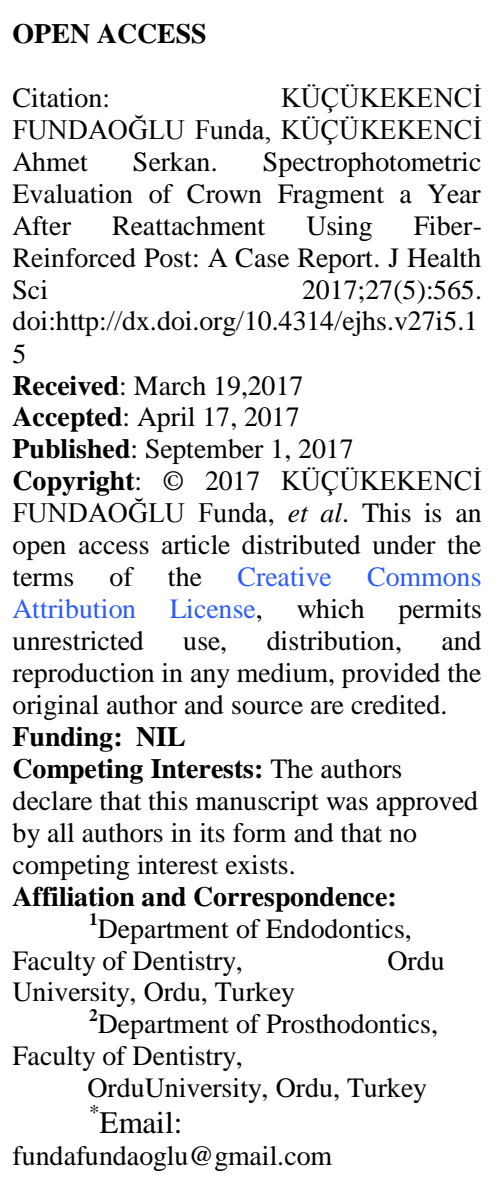

\begin{abstract}
BACKGROUND: Crown fracture is the most common type of fracture and frequently affects the anterior teeth. Crown fractures have been treated in several ways depending on the location and kind of fracture. This case emphasizes reattachment of fractured fragments using fiber-reinforced post. Also this case report underlines the related aesthetic concerns of reattaching of the fractured fragment.
\end{abstract}

CASE REPORT: Intraorally, examination revealed a complicated crown-root fracture of the left maxillary central (\#21) and lateral incisor (\#22). Moreover, the incisal one-third of the right maxillary central incisor (\#11) was fractured. Baseline color of the tooth was recorded with a spectrophotometer to compare final color of tooth treated with fiber post. The root canal of 21 and 22 was filled with a sealer and gutta-percha. Then, the fiber-reinforced post was placed into the canals, and fractured segments were bonded with self-adhesive resin cement. Direct composite resin restoration was applied to 11. A year later, a second color measurement was recorded, and color differences $(\Delta E)$ were calculated.

RESULT: In 12 months' follow-up, 11, 21 and 22 were asymptomatic with satisfying aesthetics, maxillar right incisor was vital. When crown discoloration was examined, there was clinically perceptible but acceptable discoloration without periapical pathology.

CONCLUSION: Fiber reinforced post empowers not only the protection and reinforcement of tooth structure but also provides esthetic restoration.

KEYWORDS: Fiber-reinforced post, Reattachment, Spectrophotometer

\section{INTRODUCTION}

Crown fracture is the most common type of fracture and frequently affects the anterior teeth. The reason is that the maxillary anterior teeth has exposed position in the dental arch (1). Crown-root fractures may be classified as complicated, due to pulpal involvement which is more frequent, or noncomplicated which have an absence of pulpal involvement (2). Intense pain that originates 
from crown-root fractures can be either because of pulpal exposure heat-cold or due to concomitant periodontal injury or both so that traumatized teeth supposes fast functional and esthetic restoration (3). A few factors affect the treatment of coronal tooth fractures such as the restorability of the tooth, bearing the dimension of the fracture, the pattern of fracture and availability or failure of the fractured tooth fragment. If the fractured fragment is present, reattachment of the tooth fragment is a possible treatment choice (4). The reattachment of the crown fragment to a fractured tooth is the top process to recover the inherent form, contour, and occlusal relationship. Reattachment procedure provides the most well-preserved incisal transparency which offers excellent esthetic and functional results in a single visit (5). Fiberreinforced posts (FRC) that have different advantages, such as support to dentin, have a modulus of elasticity like that of dentin use usually for the reattachment method of the fractured fragment. Because of the similar modulus of elasticity of the FRC post, resin cement and dentin increases the retention. The increases of retention are called monoblock effect (6).

Restoration of aesthetics is one of the major concerns like in this teeth. One of the advantages of FRC is that it is aesthetic, but unfortunately, there are no studies evaluating the color change of the teeth after reattachment by using an objective device such as a spectrophotometer. The aim of this case report is to describe the reattachment of two complicated crown-root fractures of maxillary central and lateral incisors after fight sport. In addition, the article presents the evaluation of the discoloration of the reattached fragment using a spectrophotometer.

\section{CASE REPORT}

A 26-year-old male patient was referred to the department of endodontic because of a traumatic injury resulting from fight sport a day ago. The patient reported increased pain and discomfort due to the traumatized teeth. The patient's history for systemic diseases or allergy was non-contributory. Extra-oral examination revealed no significant findings. The clinical and radiographic maxillofacial examination indicated that the maxilla and the mandible were intact (Figure 1a). Intraorally, examination revealed a complicated crown-root fracture of the left maxillary central (\#21) and lateral incisor (\#22). Moreover, the incisal one-third of the right maxillary central incisor (\#11) was fractured, but the tooth presented slightly tender to cold and physiological mobility (Figure 1b). The diagnose was a noncomplicated crown fracture with hypersensitive dentin for 11 . The maxillary left lateral incisor had a fracture horizontal on the buccal, $1 \mathrm{~mm}$ above the gingival margin and the central incisor had a fracture horizontal on the buccal, $3 \mathrm{~mm}$ above the gingival margin. A fracture extending from the buccal area to the subgingival space of the palatal area with pulpal exposing was observed in both the central and lateral teeth (Figure 1c). The incisal fragments had severe mobility, and during functional stress, the pain increased because of this mobility. A periapical radiograph indicated the crown of 21 and 22 with fracture track lengthening subgingivally, and the periapical side and the root structure were seen to be healthy (Figure 1d). This was diagnosed as a case of complicated crownroot fracture with irreversible pulpitis for 21 and 22.

The multiple options to recover the teeth were described to the patient. The patient volunteered to reattachment procedure. Local anesthesia was administered, and the fractured coronal fragment was detached with minimal strength from the periodontal attachment (Figure $2 \mathrm{a}, 2 \mathrm{~b}, 2 \mathrm{c}$ ). Color measurement had been recorded from coronal fragment using a spectrophotometer (Vita Easy Shade Advance 4.0, VITA, Germany). Coronal fragment was immediately soaked in a saline solution to prevent discoloration and dehydration. Following extirpation of the pulp tissues, the root canal was filled with a sealer (Sealapex ${ }^{\circledR}$, Kerr Corporation, USA) and guttapercha using the lateral condensation technique in a single visit (Figure 2d). A decision was made to place a fiber-reinforced post (Reforpost, Angelus, Brasil) into the root canal for retention. Post space was prepared sequentially using the reforpost drill. The suitable fiber-reinforced post was chosen

DOI: http://dx.doi.org/10.4314/ejhs.v27i5.15 
(Reforpost, Angelous, Brasil) to control the fit and occlusal alignment (Figure 2e). The occlusal tip of the post was abridged with a diamond bur to the wished length. After hemorrhage control, the post space was filled with self-adhesive resin cement (Panavia F.2, Kuraray, Japan) with the FRC post in place and light cured for 40secs at three levels. The minör hole was prepared in the pulp chamber of a fractured segment of 21 and 22 and was tested against the remaining crown section with the post for access. The fractured fragment was bonded in the proper status using self-adhesive resin cement (Panavia F.2) with mild pressure. Over supply of the material was removed using a cutting instrument from the sides and was light cured for 20 seconds for polymerization. A bevel was prepared on the margins of the approximating surfaces of 21 and 22 on the labial border, and the margins were covered with composite resin (Filtek Z350, Body A2, 3M ESPE, USA). Polishing of the surface was done with polishing disks which proved aesthetic accommodation of the margins. Direct restoration with resin-based composite (Filtek Z350, Body A2, 3M ESPE, USA) was carried out on the teeth where the fragment was not available (\#11) (Figure 2f).

The patient was recalled after six months and one year. On clinical examination, 11, 21 and 22 were asymptomatic with satisfying aesthetics (Figure $3 \mathrm{a}, 3 \mathrm{~b})$. The maxillar right incisor was vital. On periodontal examination, gingival tissues had normal structure and normal contouring with 2 $\mathrm{mm}$ pocket. The intraoral periapical radiograph indicated healthy tooth structure with unspoiled lamina dura (Figure 3c, 3d).

Spectrophotometric measurements were acquired on the buccal surfaces of the crown a year later. The color differences $(\Delta \mathrm{E})$ were calculated using the following formula:

$$
\Delta \mathrm{E}=\left[\left(\Delta \mathrm{L}^{*}\right)^{2}+\left(\Delta \mathrm{a}^{*}\right)^{2}+\left(\Delta \mathrm{b}^{*}\right)^{2}\right]^{1 / 2}
$$

If $\Delta \mathrm{E}$ is greater than 3.46 , there is perceptible and nonacceptable color change; a value of $\Delta \mathrm{E} 1.8$ and 3.46 represent clinically perceptible but acceptable color change (7). In this case presentation, $\Delta \mathrm{E}$ was obtained to be 2.76 for the left lateral incisor, and $\Delta \mathrm{E}$ was obtained to be 2.41 for the left central incisor. The meaning is that there is clinically perceptible but acceptable discoloration.

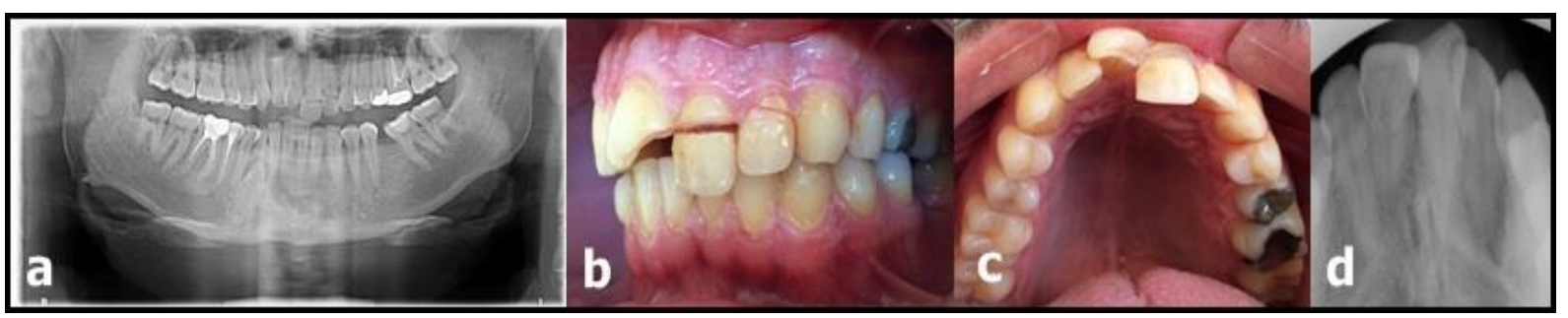

Figure 1: (a) Preoperative panoramic radiograph showing intact maxillar and mandibular bone, (b) photograph of 21 and 22 have complicated crown fracture and 11 has noncomplicated crown fracture, (c) photograph of horizontal fracture track was lengthening the subgingival space on the palatal area, and $(d)$ periapical radiograph showing healthy of periapical structure

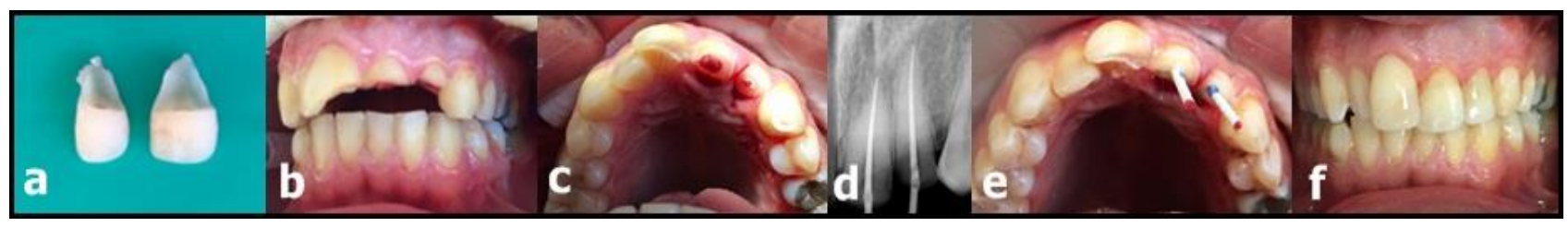

Figure 2: (a) Photograph of fractured tooth fragment, $(b, c)$ photograph of after the fractured fragment has been removed, (d) Photograph of master cone, (e) a post was inserted into the canal, and (f) photograph of final restoration

DOI: http://dx.doi.org/10.4314/ejhs.v27i5.15 


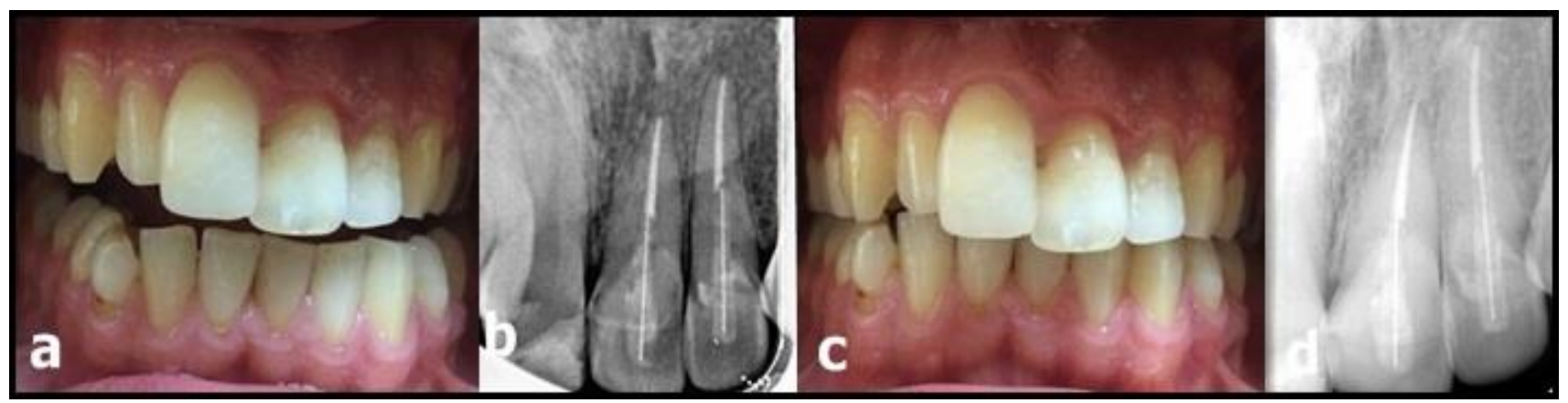

Figure 3: (a) Photograph of six months follow up, (b) 6 months follow up with radiographically, (c) photograph of 1-year follow-up and, (d) 1 year follow up with radiographically

\section{DISCUSSION}

Fracture of anterior teeth after dental injury adversely affects the sentimental bliss of a patient in addition to the discomfort and pain it causes (2). Therefore, treatment should be applied rapidly. This case shows that the adhesive reattachment of the original fragment offers a conservative, aesthetic, cost-effective and esthetic restorative choice in single visit.

Reattachment of the tooth is an option when the fractured fragment is intact and available. It has a few advantages over traditional techniques of restoration. One of these, it is protection of the translucency of natural tooth (4). A seven-year follow-up of crown reattachment indicated moderate discoloration of the crown. However, researchers have noticed discoloration without a specific device such as a spectrophotometer. Compared with visual color measurement, a color measurement made using devices have advantages such as being objective, being able to be expressed by numbers, and measurements being obtained faster. Color measurement can be done using a spectrophotometer. A spectrophotometer is a device that makes measurements in accordance with CIELab standards. CIELab color system allows the determination of the color adopted by ISO standards in international standardization (8). In this case, the spectrophotometer was used to check that this was achieved. The difference between the first and the last colors was clinically detectable but acceptable. Because of reinforcing the cervical level of the reattached tooth, it is recommended to use an intracanal post since these interlock the coronal and root fragments and also minimize the stress on the reattached tooth fragment (6). Some reattachment methods, such as direct reattachment of the fragment, internal dentinal groove, and internal enamel groove in a $\mathrm{V}$-shape, have been used with preferable effects when compared with the direct reattachment of the fragments (9). In this case, an internal dentinal groove was prepared on the coronal fragment to provide a higher mechanical strength and longevity. This retention cavity and dehydration after the canal treatment can explain the clinically noticeable but acceptable color change. According to the results of this case, reattachment treatment can be considered aesthetic. However, it is essential to regularly follow-up to approve the esthetics.

In conclusion, this case report shows the advancement in adhesive and aesthetic technology. Fiber reinforced post empowers not only the protection and reinforcement of tooth structure but also provides esthetic restoration. Spectrophotometers can be used as auxiliary devices for the aesthetic assessment. At the 6 mouth and 1 year follow-up, the resultant appearance was acceptable to the patient.

\section{ACKNOWLEDGMENTS}

The authors deny any conflict of interests related to this study.

\section{REFERENCES}

1. Lauridsen E, Hermann NV, Gerds TA, Kreiborg S, Andreasen JO. The pattern of 
traumatic dental injuries in the permanent dentition among children, adolescents, and adults. Dent Traumatol 2012;28:358-63.

2. Castro JCM, Poi WR, Manfrin TM, Zina LG. Analysis of the crown fractures and crownroot fractures due to dental trauma assisted by the Integrated Clinic from 1992 to 2002. Dent Traumatol 2005;21:121-6.

3. Olsburgh S, Jacoby T, Krejci I. Crown fractures in the permanent dentition: pulpal and restorative considerations. Dent Traumatol 2002;18:103-15.

4. Chosack A, Eidelman E. Rehabilitating of a fractured incisor using the patient's natural crown: a case report. J Dent Child 1994;71:19-21.

5. Villat $C$, Machtou $P$, Naulin-Ifi $C$. Multidisciplinary approach to the immediate esthetic repair and long-term treatment of an oblique crown-root fracture. Dent Traumatol 2004;20:56-60.

6. Tay FR, Pashley DH. Monobloks in root canals: A hypothetical or a Tangible Goal. J Endod 2007;33:391-8.

7. Ghinea G, Kent S, Frank AO, Chana GS. Visualization of back pain data--a 3-D solution. IEEE Trans Inf Technol Biomed 2007;11:595-7.

8. Okubo SR, Kanawati A, Richards MW, Childress S. Evaluation of visual and instrument shade matching. J Prosthet Dent 1998;80:642-8.

9. Rappelli G, Massaccesi C, Putignano A. Clinical procedures for the immediate reattachment of a tooth fragment. Dent Traumatol 2002;18:281-4. 